\title{
An Eph receptor sperm-sensing control mechanism for oocyte meiotic maturation in Caenorhabditis elegans
}

\author{
Michael A. Miller, Paul J. Ruest, Mary Kosinski, Steven K. Hanks, and David Greenstein ${ }^{\mathbf{1}}$ \\ Department of Cell and Developmental Biology, Vanderbilt University School of Medicine, \\ Nashville, Tennessee 37232, USA
}

\begin{abstract}
During sexual reproduction in most animals, oocytes arrest in meiotic prophase and resume meiosis (meiotic maturation) in response to sperm or somatic cell signals. Despite progress in delineating mitogen-activated protein kinase (MAPK) and CDK/cyclin activation pathways involved in meiotic maturation, it is less clear how these pathways are regulated at the cell surface. The Caenorhabditis elegans major sperm protein (MSP) signals oocytes, which are arrested in meiotic prophase, to resume meiosis and ovulate. We used DNA microarray data and an in situ binding assay to identify the VAB-1 Eph receptor protein-tyrosine kinase as an MSP receptor. We show that VAB-1 and a somatic gonadal sheath cell-dependent pathway, defined by the CEH-18 POU-class homeoprotein, negatively regulate meiotic maturation and MAPK activation. MSP antagonizes these inhibitory signaling circuits, in part by binding VAB-1 on oocytes and sheath cells. Our results define a sperm-sensing control mechanism that inhibits oocyte maturation, MAPK activation, and ovulation when sperm are unavailable for fertilization. MSP-domain proteins are found in diverse animal taxa, where they may regulate contact-dependent Eph receptor signaling pathways.
\end{abstract}

[Keywords: Meiosis; meiotic maturation; Eph receptor; soma-germline interactions; major sperm protein; ephrin]

Received July 31, 2002; revised version accepted November 14, 2002.

Sexual reproduction requires meiosis to generate haploid (1n) gamete nuclei, which unite after fertilization to form the diploid (2n) totipotent embryo. Despite this universal requirement, meiosis is regulated differently in sperm and oocytes. Whereas sperm proceed through the meiotic divisions uninterrupted, oocytes almost invariably arrest during one, and sometimes two stages following premeiotic DNA replication and meiotic recombination, depending on the species. Therefore, the completion of meiosis in oocytes must be coordinated with development and fertilization to ensure successful reproduction. To achieve this coordination, sperm and somatic cell signals regulate oocyte meiotic progression by activating downstream cyclin-dependent kinase regulatory pathways, which mediate cell cycle transitions in eukaryotes (for review, see Ferrell 1999; Masui 2001).

The oocytes of most animals, including the early-diverging sponges and cnidarians (Masui 1985), arrest during meiotic prophase, suggesting that this regulatory mechanism represents a fundamental metazoan repro-

\footnotetext{
${ }^{1}$ Corresponding author.

E-MAIL david.greenstein@vanderbilt.edu; FAX (615) 936-3421.

Article and publication are at http://www.genesdev.org/cgi/doi/10.1101/ gad.1028303.
}

ductive strategy. Human oocytes can remain arrested in prophase for several decades, and aberrant regulation of the first meiotic division is a major cause of infertility, miscarriage, and chromosomal nondisjunction (for review, see Jacobs 1992; Hunt and LeMaire-Adkins 1998). In most animals examined, meiosis resumes in response to nonautonomous signals through a process termed meiotic maturation, which prepares the oocyte for fertilization and embryogenesis. The hallmarks of meiotic maturation include nuclear envelope breakdown, cortical cytoskeletal rearrangement, and meiotic spindle assembly. Studies of Xenopus have identified two key intracellular enzymes, maturation-promoting factor $(\mathrm{MPF})$, a complex consisting of the regulatory protein cyclin B and CDK1 protein kinase, and mitogen-activated protein kinase (MAPK), that control meiotic progression (for review, see Ferrell 1999). Although considerable progress has been made in characterizing the intracellular cascades that activate these enzymes during maturation, it is less clear how meiotic progression is regulated at the oocyte cell surface.

The nonautonomous signaling mechanisms that control meiotic maturation fall into sperm-dependent and sperm-independent classes (Masui 1985). The sperm-dependent class is more common among invertebrates, including many species of sponges, nematodes, annelids, 
and molluscs. In contrast, the sperm-independent class is more common among vertebrates. In this class, oocytes undergo maturation in response to somatic cell signals, but arrest again at a later stage in meiosis. Sperm nonetheless trigger release from these secondary arrests by a process called egg activation, which occurs during fertilization (for review, see Runft et al. 2002). Thus, sperm signal the resumption of meiosis in most animal oocytes at the maturation or egg activation stage.

To complement studies in vertebrate systems and define ancestral and derived regulatory features, we have been studying meiotic maturation in Caenorhabditis elegans (for review, see Hubbard and Greenstein 2000). Oocyte development and fertilization occur in an assembly line-like fashion, which can be viewed in the intact animal in real time (Ward and Carrel 1979; McCarter et al. 1999). Oocytes in diakinesis of meiotic prophase are located in the proximal gonad arm adjacent to the sperm storage compartment or spermatheca (Fig. 1). Smooth muscle-like gonadal sheath cells surround the developing oocytes (Fig. 1) and form gap junctions with them (Hall et al. 1999). Sperm promote meiotic maturation and sheath cell contraction, which act in concert to facilitate ovulation (McCarter et al. 1999). Fertilization then occurs as ovulating oocytes enter a sperm storage compartment called the spermatheca. When sperm are absent, oocytes can arrest in meiotic prophase for days (McCarter et al. 1999). Because the C. elegans hermaphrodite gonad produces about 300 sperm prior to oogenesis, maturation and ovulation occur constitutively in adults until sperm are depleted. In mutant hermaphrodites that do not produce sperm, and related nematode species with separate male and female sexes, oocytes arrest in meiotic prophase until insemination occurs and sperm migrate to the spermatheca.

C. elegans sperm promote oocyte meiotic maturation and sheath cell contraction using the major sperm protein (MSP) as a signaling molecule (Miller et al. 2001). MSPs are members of a highly conserved gene family (Miller et al. 2001) that are abundantly expressed in nematode sperm (Klass and Hirsh 1981). Proteins with related MSP domains are found in diverse eukaryotes, including humans, raising the possibility that these proteins also have signaling functions. MSP signals the activation of the conserved MAPK cascade in oocytes (Miller et al. 2001), which has been linked to the establishment of protein asymmetries in early embryos (Page et al. 2001). Null mutations in mpk-1 MAPK, mek-2 MAPKK, and lin-45/raf MAPKKK cause germ cells to arrest in the pachytene stage of meiosis (Church et al. 1995; Hsu et al. 2002). Thus, the functional role of the MAPK cascade during later meiotic events remains to be determined in C. elegans. Here we show that MSP signals oocyte meiotic maturation and MAPK activation by acting as an antagonist of the VAB-1 Eph receptor protein-tyrosine kinase and a sheath cell-dependent signaling pathway, defined by the POU-class homeoprotein CEH-18. Together, the vab-1 and ceh-18 pathways define a sperm-sensing checkpoint mechanism that inhibits oocyte meiotic maturation and ovulation when sperm are unavailable for fertilization.

\section{Results}

\section{MSP binds to oocyte and sheath cell membranes} of the proximal gonad

To determine how MSP signals, we analyzed in situ binding of fluorescein-labeled MSP-6His (MSP-FITC) to dissected gonads. One-hundred nanomolar MSP-FITC promotes oocyte maturation and gonadal sheath cell contraction when microinjected into fog-2(q71) females, which lack sperm due to a sex determination defect (Schedl and Kimble 1988). MSP-FITC binds to oocyte and proximal sheath cell membranes at low nM concentrations in wild-type hermaphrodites and fog-2(q71) females (Figs. 2a, 3a-c). Preincubation with a 25 -fold molar excess of unlabeled MSP outcompetes labeled MSP-FITC (Fig. 2b), and binding intensity plateaus above concentrations of $50 \mathrm{nM}$ (Fig. 3c), indicating that MSP-FITC binding is specific and saturable. Binding is not observed to male gonads, spermatozoa, distal gonads, and other cells of the reproductive tract (Fig. 2b-e). Also, BSA-FITC does not bind cells specifically in this assay (data not

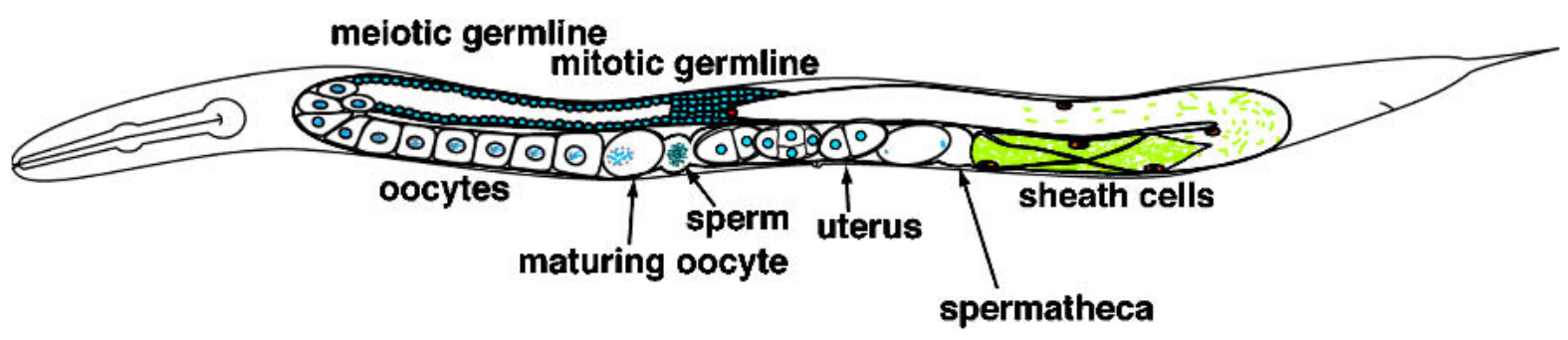

Figure 1. Oocyte meiotic maturation in the adult hermaphrodite gonad. The anterior (left) and posterior (right) gonad arms are drawn to depict the germ line and somatic gonadal sheath cells, respectively. Sperm are stored in the spermatheca and use MSP to signal oocyte meiotic maturation and sheath cell contraction, which act together to facilitate ovulation. Meiotic maturation and ovulation occur in an assembly line-like fashion in the proximal gonad. Nuclear envelope breakdown of the maturing oocyte is indicated by dotted lines. The oocyte is fertilized during ovulation as it enters the spermatheca, and embryos develop in the uterus until they are laid through the vulva (not labeled). In hermaphrodites, spermatogenesis takes place in the gonad arms and sperm enter the spermatheca during the first ovulation. Spermatogenesis does not occur in fog-2(q71) females, so mating is required for reproduction. Sperm are inseminated through the vulva during mating and then crawl to the spermatheca. 

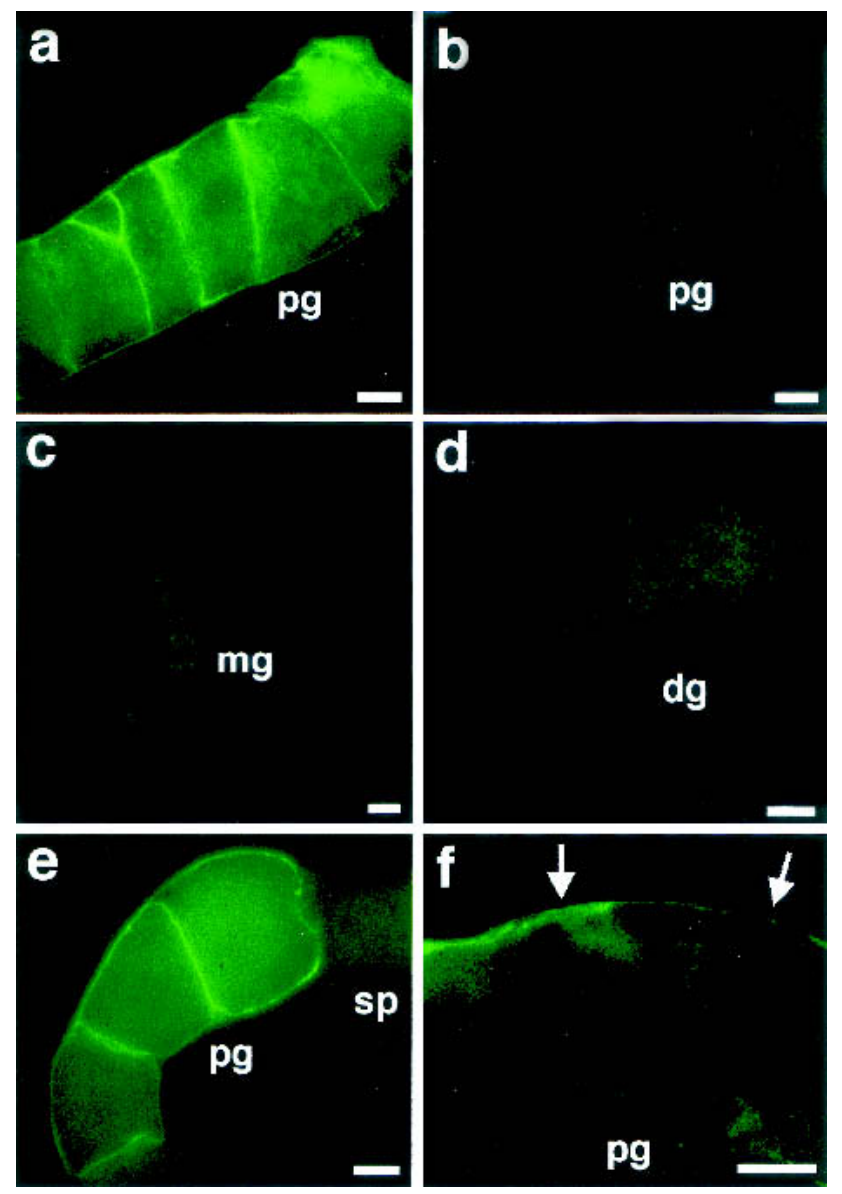

Figure 2. In situ binding of MSP-FITC. (a) Two-hundred nanomolar MSP-FITC binds to oocyte and sheath cell membranes of the proximal gonad arms of mated $f \circ g-2(q 71)$ females. $(b)$ Binding to membranes in the proximal gonad following preincubation with a 25 -fold molar excess of unlabeled MSP is not observed. $(c, d)$ Binding is not observed in the male gonad $(c)$ or the distal hermaphrodite gonad $(d) .(e, f)$ MSP-FITC binds to oocytes and sheath cell membranes in control emo-1(oz1)/+ heterozygotes $(e)$, but binding to oocyte membranes is significantly reduced or eliminated in emo-1(oz1) mutants $(f)$, which have impaired germline secretory function. Binding to sheath cells, which have normal secretory function, is not eliminated $(f$, arrows). pg, proximal gonad; $\mathrm{mg}$, male gonad; $\mathrm{dg}$, distal hermaphrodite gonad; sp, spermatheca. Bars, $15 \mu$.

shown). The dose response for MSP signaling using an in vivo bioassay (Miller et al. 2001) is consistent with the concentration range over which in situ binding is observed (Fig. 3c). To test whether MSP binds a receptor on oocytes, we examined binding to emo-1(oz1) gonads, which have impaired germline secretory function due to a mutation in a SEC61p $\gamma$ homolog (Iwasaki et al. 1996). MSP-FITC binds to oocytes and sheath cells in control emo-1(oz1)/+ heterozygotes (Fig. 2e), but binding to oocytes is reduced or eliminated in emo-1(oz1) homozygotes (Fig. 2f). In contrast, binding to somatic sheath cells, which retain secretory function in the emo-1(oz1) background (Iwasaki et al. 1996), is not eliminated (Fig. 2f). Taken together, these results indicate that MSP binds a receptor(s) on oocyte and proximal sheath cell plasma membranes.

\section{Identification of an MSP receptor}

We reasoned that mRNA encoding the MSP receptor(s) was likely to be highly enriched in oocytes. Therefore, we searched the DNA microarray data set of Reinke et al. (2000) for oocyte-enriched genes with the potential to span the lipid bilayer and regulate MAPK or cell-cycle progression. RNA interference (RNAi) and loss-of-function mutants were used in conjunction with the MSP binding assay to test receptor candidates. Out of 258 oocyte-enriched genes, only the VAB-1 Eph receptor protein-tyrosine kinase (George et al. 1998), the GLP-1 LIN12/Notch-family receptor (Austin and Kimble 1987; Yochem and Greenwald 1989), and the TSP-12 (T14G10.6) tetraspanin fit our criteria. The GLP-1 Notch receptor was not tested because anti-GLP-1 antibodies do not stain oocytes (Crittenden et al. 1994). The CAM-1 Rorclass receptor tyrosine kinase (Forrester et al. 1999), the RME-2 yolk receptor (Grant and Hirsh 1999), the CAV-1 caveolin homolog (Scheel et al. 1999), and the GEX-3 HEM2/NAP1 homolog (Soto et al. 2002) were also tested as each protein fit a subset of criteria. Only RNAi of the VAB-1 Eph receptor results in a reduction in MSP-FITC binding (data not shown). To verify that VAB-1 is required for complete MSP binding, vab-1 mutants were analyzed for binding in situ (Fig. 3a-c). Compared to the wild type, a significant reduction in MSP-FITC binding is observed in gonads from vab-1(dx31) null mutants (Fig. 3a,c; $P<0.001$ ), which result from a deletion of exons 1-4, including the translation start site (George et al. 1998). MSP-FITC binding does not require VAB-1 catalytic activity because binding intensity is not reduced in vab-1(e2) mutants (Fig. 3a), which contain a missense mutation (G917E) in the intracellular kinase domain impairing catalysis (George et al. 1998; Wang et al. 1999). Also, binding intensity is not reduced in vab-1(ju8) or vab-1(e699) mutants (Fig. 3b), which contain missense mutations at adjacent sites (E62K and T63I) in the extracellular ephrin binding domain, impairing signaling by ephrin ligands (George et al. 1998; Chin-Sang et al. 1999; Wang et al. 1999). vab-1 mRNA was independently determined to be highly enriched in hermaphrodite gonads by in situ hybridization analysis (Y. Kohara, unpubl.; data available at http://nematode.lab.nig.ac.jp). These results indicate that the binding of MSP to a subset of receptor sites requires VAB-1, but not its catalytic activity or its ability to interact with ephrins. The residual binding in $v a b-1(d \times 31)$ gonads (Fig. 3a,c) is likely due to an additional receptor(s) because it is eliminated when gonads are preincubated with a 25 -fold molar excess of unlabeled MSP (data not shown).

To determine whether VAB-1 is sufficient for MSP binding, we analyzed MSP-FITC binding to live COS-7 cells transiently transfected with a VAB-1 expression plasmid (Wang et al. 1999). Surface MSP-FITC binding is observed in approximately $20 \%-40 \%$ of these cells (Fig. $3 \mathrm{~d})$, consistent with the transfection efficiency. Binding 
Miller et al.
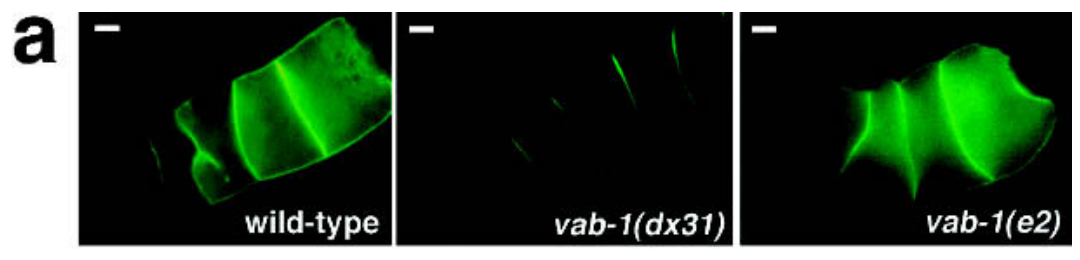

Figure 3. MSP binds to the VAB-1 Eph receptor. (a) Compared to wild-type gonads, MSP binding (200 nM MSP-FITC) is reduced in vab$1(d \times 31)$ null mutant gonads, but not in $v a b$ 1(e2) kinase-impaired gonads. Proximal is to the right. (b) MSP binding is not reduced in the ephrin signaling mutants vab-1(ju8) and $v a b$ 1(e699). (c) The binding intensity of $v a b$ $1(d \times 31)$ gonads is significantly lower than wildtype $\left({ }^{*} ; P<0.001\right)$. Binding intensity was measured at three MSP-FITC concentrations using arbitrary units that correspond to fluorescent intensity. $v a b-1(d \times 31)$ null mutants exhibit a reduction in saturable MSP binding. Because of the thinness of the sheath cells $(\sim 0.2-1 \mu \mathrm{m})$, we were unable to separately quantify the reduction in sheath cell binding. Error bars indicate S.D. $(d, e)$ Expressing VAB-1 in COS-7 cells is sufficient to confer MSP binding activity. (d) Two-hundred nanomolar MSP binds to the surface of live COS-7 cells (arrow) expressing VAB-1 (upper panel), but not n-Src (lower panel). (e) COS-7 cells expressing VAB$1::$ DsRed bind MSP (arrows), whereas those that do not express VAB-1 : DsRed do not bind. Arrows in $d$ and $e$ indicate specific binding, and arrowheads indicate internal autofluorescence caused by the transfection procedure. Bars, $10 \mu$.
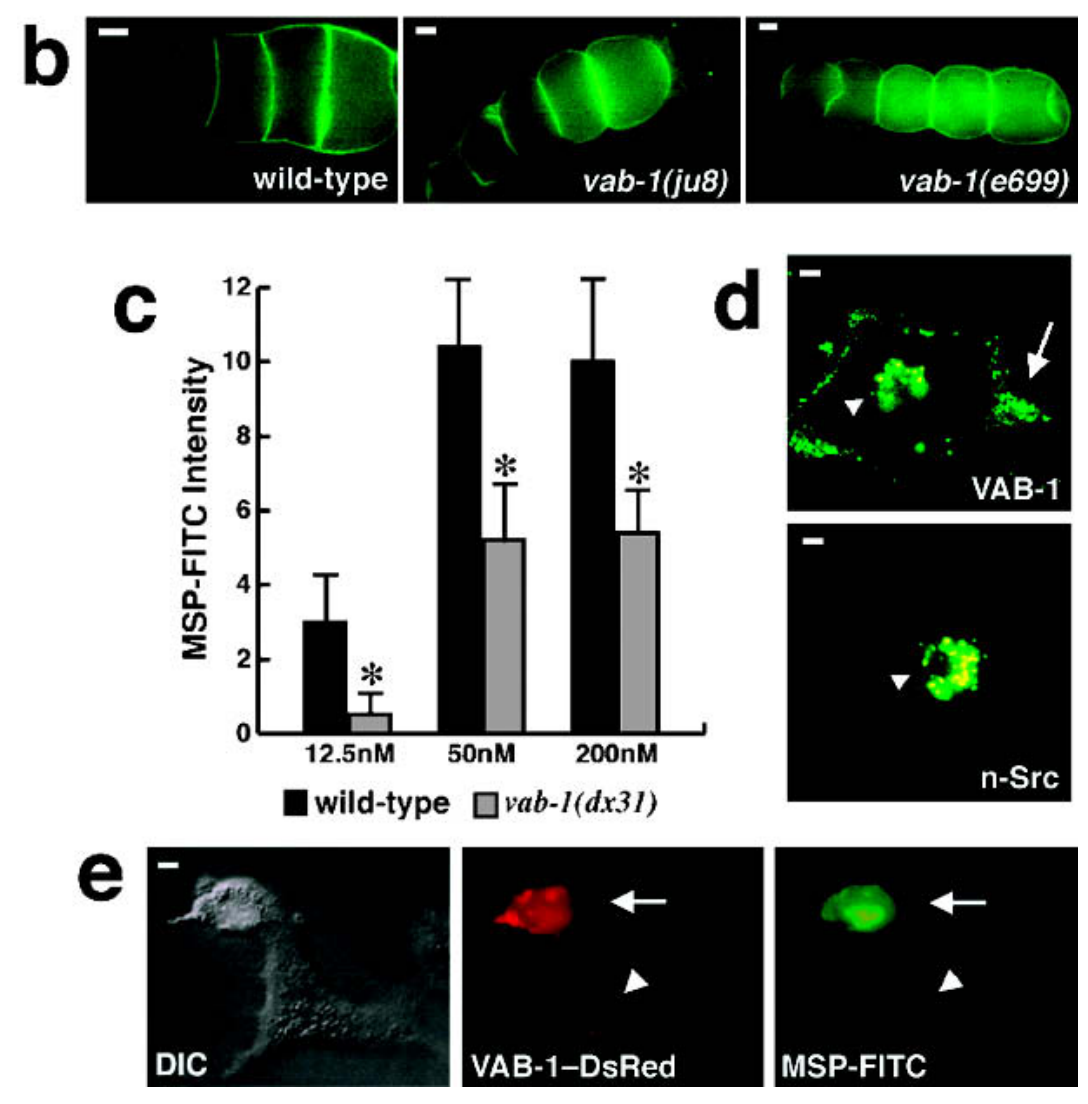

is not observed following control transfections using a mouse $\mathrm{n}$-Src tyrosine kinase expression plasmid (Fig. 3d) or in untransfected cells (data not shown). We also transfected COS-7 cells with a plasmid encoding a VAB-1::DsRed fusion protein to monitor VAB-1 expression. COS-7 cells expressing VAB-1::DsRed bind MSPFITC, whereas binding is not observed in cells that do not express VAB-1::DsRed (Fig. 3e). COS-7 cells visibly expressing VAB-1::DsRed had a rounder and more compact morphology (Fig. 3e) compared to nonexpressing cells, which may be due to ligand-independent receptor activation caused by overexpression. These results indicate that VAB-1 expression is sufficient for MSP binding to COS-7 cells.

MSP-FITC binding to oocytes and sheath cells is reduced in $v a b-1(d \times 31)$ and $v a b-1$ RNAi gonads (Fig. 3a,c; data not shown). Therefore, VAB-1 is predicted to be expressed on oocyte and sheath cell membranes. To investigate the VAB-1 expression pattern in gonads, we examined the juIs24 transgenic reporter strain, which contains a translational fusion of the vab-1 locus to green fluorescent protein (GFP; George et al. 1998).

VAB-1::GFP likely reflects the endogenous expression pattern, because vab-1 null mutant somatic (George et al. 1998) and gonadal (see below) phenotypes are rescued in this strain. Although VAB-1::GFP fluorescence is difficult to detect in all expressing cell types in intact hermaphrodites, it is detectable in dissected gonads using sensitive optical techniques (see Materials and Methods). VAB-1::GFP is observed in oocytes and sheath cells of the proximal gonad arm in transgenics (Fig. 4b,c), but not in controls (Fig. 4a). GFP fluorescence appeared enriched between oocytes, and in the thin sheath cells surrounding them, in a pattern similar to that observed in wild-type gonads incubated with MSP-FITC (Figs. 2, 3). This result, taken together with our binding data, strongly supports the hypothesis that MSP binds VAB-1 on oocyte and sheath cell membranes.

\section{Negative regulation of oocyte meiotic maturation and MAPK activation}

We hypothesized that VAB-1 signaling negatively regulates oocyte maturation and MAPK activation in the ab- 

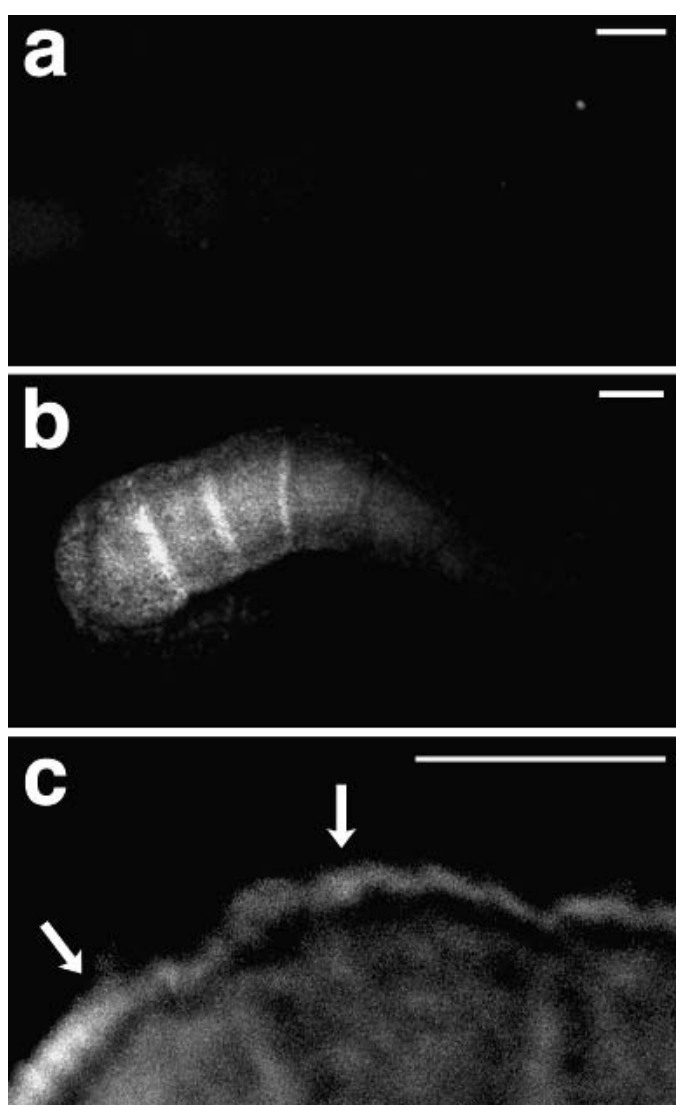

Figure 4. VAB-1::GFP is expressed in oocytes and sheath cells. (a) Fluorescence is not observed in dissected, wild-type gonads. $(b, c)$ VAB-1::GFP expression is detectable in oocytes $(b)$ and sheath cells $(c)$ in gonads dissected from the transgenic strain juIs24. Images were processed using deconvolution software (see Materials and Methods). Bars, $25 \mu$.

sence of MSP. This is supported by the observation that oocyte maturation still occurs in emo-1(oz1) oocytes (Iwasaki et al. 1996; data not shown), which have impaired secretory function and fail to bind MSP effectively (Fig. 2f). Further, a monoclonal antibody against the activated, diphosphorylated form of MAPK (MAPK-YT) stains oocytes from unmated emo-1(oz1) females (Fig. 5a) and emo-1 (oz1) hermaphrodites (data not shown), indicating that MAPK activation is not dependent on MSP in the emo-1(oz1) genetic background. These results support the hypothesis that MSP promotes oocyte maturation and MAPK activation by acting as an antagonist of VAB-1 signaling.

To test whether VAB-1 negatively regulates oocyte maturation and MAPK activation, we analyzed $v a b-1$ mutant hermaphrodites. Time-lapse video microscopy of $v a b-1$ mutant gonads indicates that $v a b-1$ is not required for oocyte maturation, ovulatory sheath cell contractions, ovulation, or fertilization. However, vab-1 is required for the normal sperm-dependent increase in the basal gonadal sheath cell contraction rate (Table 1, cf. lines $1-4 ; P<0.001$ ), a response mediated by MSP (Miller et al. 2001). In wild-type hermaphrodites, the oocyte maturation rate is high when sperm are abundant, but decreases as sperm are depleted, ensuring that oocytes are not wasted when fertilization is not possible. If VAB-1 negatively regulates oocyte maturation as hypothesized, then oocytes should continue to mature and ovulate in old $v a b-1$ hermaphrodites that have run out of sperm. We counted the number of unfertilized oocytes laid by wild-type and vab-1 mutant hermaphrodites dur-
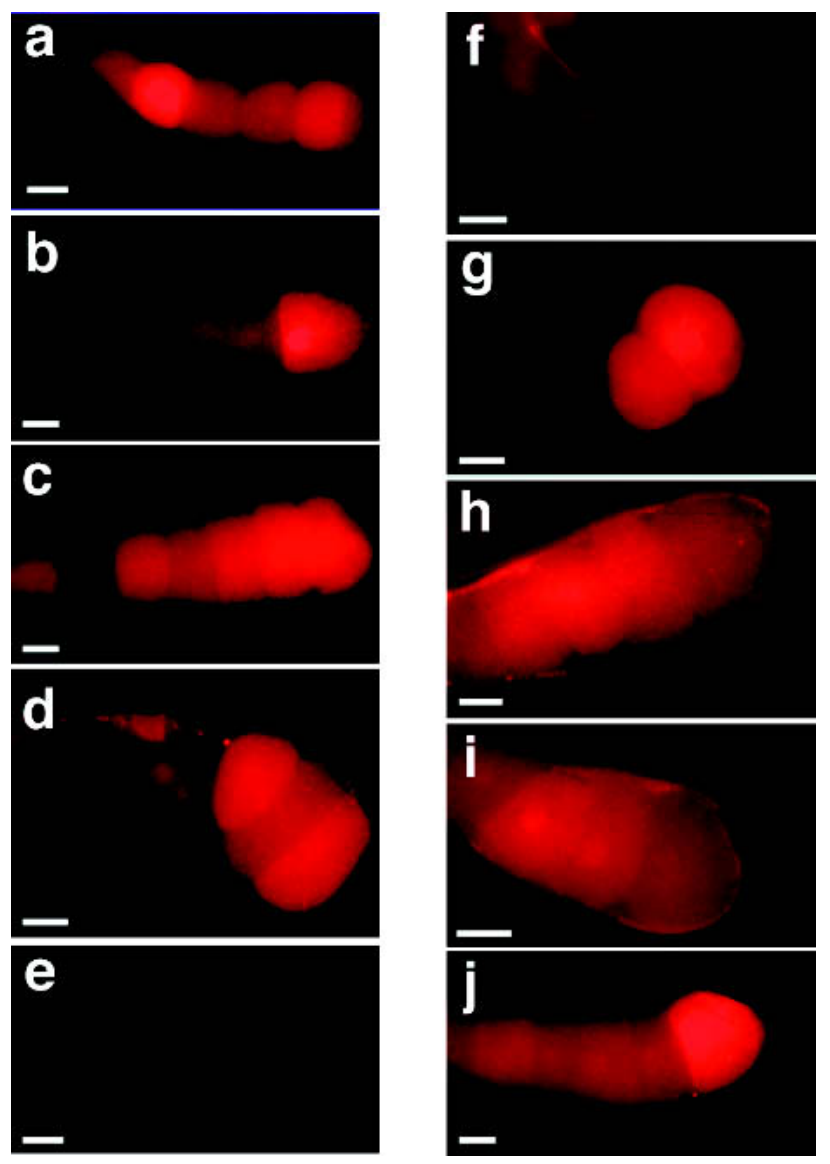

Figure 5. VAB-1 and CEH-18 negatively regulate MAPK activation. The MAPK-YT antibody recognizes the diphosphorylated, active form of MAPK (red). Staining is not observed in mpk-1 (ga117) MAPK null mutant gonads or unmated fog-2(q71) female gonads. (a) MAPK activation is not dependent on sperm in unc-24(e138) fem-3(e1996);emo-1(oz1) oocytes, which have impaired secretory function. (b) In wild-type hermaphrodites, MAPK activation is dependent on sperm, but activation occurs in the most proximal one to three oocytes. (c) In contrast, several oocytes contain activated MAPK in vab-1(dx31) hermaphrodites. $(d, e)$ MAPK activation occurs in the absence of sperm in unmated fog-2(q71);ceh-18(mg57);vab-1 (RNAi) females (d), but not in unmated fog-2(q71);vab-1(dx31) females $(e)$. $(f, g)$ Unmated fog-2(q71);ceh-18(mg57) female gonads contain low levels of activated MAPK, but rarely in the most proximal oocytes $(f)$. However, activation is observed following mating $(g)$. $(h, i)$ MAPK-YT staining in fog-2(q71);ceh-18(mg57);vab-1(dx31)/+ heterozygous females $(h)$ is not affected by mating (i) to wildtype males. (j) efn-2(ev658) hermaphrodites exhibit slightly enhanced levels of MAPK-YT staining compared to wild-type hermaphrodites $(b)$. Proximal is to the right. Bars, $20 \mu$. 
Table 1. Fertility of vab-1 and efn-2 mutants

\begin{tabular}{|c|c|c|c|c|c|c|}
\hline Genotype & $\begin{array}{l}\text { Sperm } \\
\text { (yes/no) }\end{array}$ & $\begin{array}{c}\text { Sheath cell } \\
\text { contractions/min }\end{array}$ & $\begin{array}{c}\mathrm{N} \\
\text { (gonads) }\end{array}$ & $\begin{array}{l}\text { Fertilized } \\
\text { eggs laid }\end{array}$ & $\begin{array}{l}\text { Unfertilized } \\
\text { oocytes laid }\end{array}$ & $\begin{array}{c}\mathrm{N} \\
\text { (animals) }\end{array}$ \\
\hline 1. $f \circ g-2(q 71)$ & No & $3.1 \pm 2.3$ & 11 & 0 & N.D. ${ }^{\mathrm{a}}$ & $>200$ \\
\hline 2. Wild-type & Yes & $9.9 \pm 1.3$ & 10 & $268.8 \pm 13.3$ & $24.2 \pm 15.2$ & 13 \\
\hline 3. $v a b-1(d \times 31)$ & Yes & $4.2 \pm 2.1^{\mathrm{b}}$ & 11 & $246.8 \pm 33.8$ & $111.5 \pm 44.0^{\mathrm{b}}$ & 11 \\
\hline 4. $v a b-1(R N A i)$ & Yes & $3.0 \pm 1.7^{\mathrm{b}, \mathrm{c}}$ & 11 & $183.5 \pm 20.8$ & $76.5 \pm 27.2^{\mathrm{b}}$ & 10 \\
\hline 5. $v a b-1(e 2)$ & Yes & $7.1 \pm 1.9^{\mathrm{b}}$ & 10 & $260.2 \pm 19.4$ & $66.0 \pm 31.6^{\mathrm{b}}$ & 9 \\
\hline 6. $v a b-1(e 699)$ & Yes & $9.3 \pm 1.9^{\mathrm{c}}$ & 9 & $120.3 \pm 12.5$ & $59.9 \pm 10.9^{\mathrm{b}}$ & 7 \\
\hline 7. $v a b-1(j u 8)$ & Yes & $9.6 \pm 2.1^{\mathrm{c}}$ & 9 & $163.0 \pm 25.2$ & $63.1 \pm 21.5^{\mathrm{b}}$ & 9 \\
\hline 8. $v a b-2(e 96)$ & Yes & $10.3 \pm 1.6^{\mathrm{c}}$ & 7 & $176.9 \pm 37.2$ & $19.6 \pm 12.6^{\mathrm{c}}$ & 12 \\
\hline 9. efn-2(ev658) & Yes & $10.4 \pm 1.8^{\mathrm{c}}$ & 7 & $79.7 \pm 14.1^{\mathrm{d}}$ & $169.3 \pm 57.9^{\mathrm{b}}$ & 12 \\
\hline 10. $\operatorname{rrf}-1(p k 1417)$ & Yes & $10.3 \pm 1.6$ & 10 & $220.9 \pm 27$ & $33.9 \pm 31$ & 11 \\
\hline 11. $v a b-1$ (RNAi); $r r f-1(p k 1417)$ & Yes & $10.5 \pm 1.4^{\mathrm{f}}$ & 11 & $143.2 \pm 25.7$ & $109.7 \pm 56.9^{\mathrm{c}}$ & 10 \\
\hline 12. efn-2 (RNAi); rrf-1(pk1417) & Yes & N.D. & N.D. & $160.7 \pm 23.3$ & $145.6 \pm 71.3^{\mathrm{e}}$ & 9 \\
\hline
\end{tabular}

Basal sheath contraction rates and brood sizes were measured at $25^{\circ} \mathrm{C}$ as described.

Brood sizes were measured at $22^{\circ} \mathrm{C}$ for $r r f-1(p k 1417)$ mutants.

${ }^{a}$ Due to the low maturation rate in $f_{0} g-2(q 71)$ females, unfertilized oocytes disintegrate or clump in the uterus before they can be laid. Thus, the number of oocytes laid by fog-2(q71) females was not determined (N.D.), but is estimated to be $<20$ based on maturation rate measurements (see Table 2).

${ }^{\mathrm{b}} \mathrm{P}<0.001$ or ${ }^{\mathrm{c}} \mathrm{P}>0.01$ compared to the wild-type value using student's t-test.

${ }^{\mathrm{d}}$ efn-2(ev658) mutants produce fewer sperm than the wild type.

${ }^{\mathrm{e}} \mathrm{P}<0.001$ or ${ }^{\mathrm{f}} \mathrm{P}>0.01$ compared to the $r r f-1(p k 1417)$ value using student's t-test.

ing a 7-d time period following the L4 larval stage. vab1(dx31), vab-1(e2), vab-1(ju8), and vab-1(e699) hermaphrodites lay significantly more unfertilized oocytes than the wild type (Table 1 , cf. lines 2-7; $P<0.001$ ). However, the number of unfertilized oocytes laid during the first $60 \mathrm{~h}$ is not significantly different than the number laid by the wild type, indicating that this disparity results from older sperm-depleted hermaphrodites $(P>0.01)$. To determine whether vab-1 negatively regulates MAPK activation, we stained wild-type and $v a b$ 1(dx31) hermaphrodites with the MAPK-YT antibody (Miller et al. 2001). One to three of the most proximal oocytes stain with this antibody in wild-type animals (Fig. 5b). In contrast, three to eight oocytes stain in vab1(dx31) hermaphrodites (Fig. 5c). Thus, phenotypic analysis of $v a b-1$ mutant hermaphrodites suggests that VAB-1 is a negative regulator of oocyte maturation and MAPK activation, and a positive regulator of MSP-mediated gonadal sheath cell contractions.

Two genetic criteria should be satisfied to conclude that MSP is an antagonist of VAB-1 signaling in oocytes. First, VAB-1 should be required for the inhibition of oocyte maturation in unmated females. Second, females containing loss-of-function mutations in genes in the MSP signaling pathway should not respond to MSP. We tested these criteria by examining the oocyte maturation rates in mated and unmated vab-1 mutant fog-2(q71) females. The maturation rate of unmated vab-1(dx31) females is significantly higher than that of unmated females (Table 2, cf. lines 2, 4; $P<0.001$ ). During these maturations, ovulation is frequently delayed following M-phase entry. Because MSP likely binds multiple receptors (Fig. $3 \mathrm{c}$ ) and the maturation rate in unmated vab$1(d \times 31)$ females is lower than in wild-type hermaphrodites, mated females, or vab-1(dx31) hermaphrodites,
(Table 2, cf. lines 4 and 1,3,5; $P<0.001$ ), we hypothesized that MSP also signals through a vab-1-independent pathway. To test this hypothesis, we microinjected $100 \mathrm{nM}$ MSP into the uterus of unmated vab-1(dx31);fog-2(q71) females. MSP still promotes oocyte maturation in these mutant females [1.5 maturations/h $(\mathrm{n}=8)$ vs. 0.4 maturations/h for control $v a b-1(d \times 31) ; f o g-2(q 71)$ females]. Collectively, these results strongly support the hypothesis that MSP signals through vab-1-dependent and $v a b$ 1 -independent pathways.

\section{vab-1 and ceh-18 define parallel signaling pathways}

Somatic follicle cells negatively regulate oocyte maturation in many mammalian species (Pincus and Enzmann 1935; Edwards 1965). By analogy, we considered the hypothesis that the somatic gonadal sheath cells negatively regulate oocyte maturation in C. elegans. Consistent with this hypothesis, the sheath cell-expressed POU-homeoprotein CEH-18 (Greenstein et al. 1994) is required for the complete inhibition of maturation (Table 2, cf. lines 2 and $8 ; P<0.001)$. ceh-18(mg57) null gonads, like $v a b-1(d \times 31)$ null gonads, still respond to sperm, indicating that they receive MSP signals (Table 2, cf. lines 8 and 9). CEH-18 is not expressed in oocytes (Greenstein et al. 1994) and is not required for MSP-FITC binding to oocytes (data not shown). Therefore, the null mutation ceh18(mg57) defines a somatic gonad-dependent pathway that inhibits oocyte maturation. Consistent with this possibility, ceh-18 mutants are fertile and oocyte development is largely normal.

To determine whether VAB- 1 and CEH-18 act in parallel, we inactivated both genes in unmated females (Fig. 6; Table 2). The oocyte maturation rate in unmated ceh18(mg57) vab-1(RNAi) females is significantly higher 
Table 2. Oocyte meiotic maturation rate measurements

\begin{tabular}{|c|c|c|c|}
\hline Genotype & $\begin{array}{l}\text { Sperm } \\
\text { (yes/no) }\end{array}$ & $\begin{array}{l}\text { Oocyte maturations per } \\
\text { gonad arm per hr }\end{array}$ & $\frac{\mathrm{N}}{\text { (animals) }}$ \\
\hline 1. Wild-type hermaphrodite & Yes & $2.52 \pm 0.41$ & 16 \\
\hline 2. Female, unmated & No & $0.09 \pm 0.08$ & 25 \\
\hline 3. Female, mated & Yes & $2.27 \pm 0.48$ & 20 \\
\hline 4. $v a b-1(d \times 31)$ female, unmated & No & $0.42 \pm 0.20$ & 12 \\
\hline 5. $v a b-1(d \times 31)$ hermaphrodite & Yes & $2.24 \pm 0.46$ & 11 \\
\hline 6. $v a b-1(e 2)$ female, unmated & No & $0.14 \pm 0.11$ & 11 \\
\hline 7. $v a b-1(e 2)$ hermaphrodite & Yes & $2.43 \pm 0.22$ & 10 \\
\hline 8. ceh-18(mg57) female, unmated & No & $0.75 \pm 0.32$ & 18 \\
\hline 9. $c e h-18(m g 57)$ female, mated & Yes & $1.89 \pm 0.31$ & 11 \\
\hline 10. $v a b-1(R N A i) ; c e h-18(m g 57)$ female, unmated & No & $2.18 \pm 0.32$ & 14 \\
\hline 11. $v a b-1(R N A i) ; c e h-18(m g 57)$ female, mated & Yes & $2.25 \pm 0.52$ & 13 \\
\hline 12. vab-1(e2); ceh-18(mg57) female, unmated & No & $1.70 \pm 0.35$ & 10 \\
\hline 13. $v a b-1(e 2) ; c e h-18(m g 57)$ female, mated & Yes & $2.36 \pm 0.48$ & 7 \\
\hline 14. $v a b-1(e 2) /+; c e h-18(m g 57)$ female, unmated & No & $2.17 \pm 0.45$ & 15 \\
\hline 15. $v a b-1(\mathrm{e} 2) /+;$ ceh-18(mg57) female, mated & Yes & $2.32 \pm 0.55$ & 13 \\
\hline 16. $v a b-1(d \times 31) /+$; ceh-18(mg57) female, unmated & No & $2.05 \pm 0.44$ & 10 \\
\hline 17. vab-1(e699); ceh-18(mg57) female, unmated & No & $1.24 \pm 0.30$ & 9 \\
\hline 18. efn-2(ev658) female, unmated & No & $0.23 \pm 0.16$ & 12 \\
\hline 19. efn-2(ev658); ceh-18(mg57) female, unmated & No & $1.60 \pm 0.60$ & 15 \\
\hline 20. $r r f-1(p k 1417)$ fog-3(q443) female, unmated & No & $0.18 \pm 0.23$ & 12 \\
\hline 21. $v a b-1(R N A i)$; fog-3(q443) female, unmated & No & $0.52 \pm 0.26$ & 10 \\
\hline 22. $v a b-1$ (RNAi); $r r f-1(p k 1417)$ fog-3(q443) female, unmated & No & $0.48 \pm 0.26$ & 12 \\
\hline
\end{tabular}

Maturation rates were measured in hermaphrodites and fog2(q71) females containing mutations in $v a b-1$, efn-2, and ceh-18 or following RNAi. Where indicated, fog-3(q443) females were used. vab-1(dx31) is a null mutant, vab-1(e2) is a kinase-deficient hypomorph, and vab-1(e699) is an ephrin signaling hypomorph. ceh-18(mg57) deletes the POU domain and homeodomain, whereas efn-2(ev658) deletes most of the protein coding region. Sperm were introduced into females by mating as indicated. Standard deviations are shown.

than in unmated $v a b-1(d \times 31)$ and ceh-18(mg57) females (Table 2, cf. lines 10 and 4,$8 ; P<0.001)$. Further, the rate is not significantly different in the presence of sperm, indicating that oocyte maturation is independent of MSP signals in gonads lacking VAB-1 and CEH-18 function (Table 2, cf. lines 10 and $11 ; P>0.05$ ). RNAi of the CAM-1 receptor tyrosine kinase (Forrester et al. 1999), or that of CLR-1 receptor tyrosine phosphatase (Kokel et al. 1998) does not affect the maturation rate of unmated ceh-18(mg57) females (data not shown), indicating that the VAB-1 RNAi phenotype is specific. To confirm that vab-1 and ceh-18 interact genetically, we constructed ceh-18(mg57) female animals lacking VAB-1 kinase activity [ceh-18(mg57); vab-1(e2)] or VAB-1 function [ceh18(mg57); vab-1(dx31)], respectively. VAB-1 kinase activity is necessary for inhibiting oocyte maturation, because the maturation rate in unmated vab-1(e2); ceh18(mg57) females is significantly higher than that of unmated ceh-18(mg57) females (Table 2, cf. lines 12 and $8 ; P<0.001)$. The oocyte maturation rate in unmated $v a b-1(d \times 31)$;ceh-18(mg57) females is also high, although these mutants are too sick for quantitative comparison. Unmated ceh-18(mg57);vab-1(dx31)/+ and ceh18(mg57);vab-1(e2)/+ heterozygotes have significantly higher maturation rates than unmated ceh-18(mg57) females (Table 2, cf. lines $14-16$ and $8 ; P<0.001$ ), indicating that the VAB-1 pathway is sensitive to gene dosage in the absence of CEH-18. MSP-FITC binding to oocytes is not reduced in these heterozygotes compared to the wild type (data not shown). These genetic studies indicate that VAB-1 and CEH-18 define parallel and partially redundant pathways required for the inhibition of oocyte maturation.

vab-1 and ceh-18 negatively regulate MAPK activation

To determine whether VAB-1 and CEH-18 act together to negatively regulate oocyte MAPK activation, we inactivated vab-1 using RNAi in unmated ceh-18(mg57) females and stained their gonads with the MAPK-YT antibody. MAPK-YT staining is observed in the first one to three oocytes of the proximal gonad arm in these females (Fig. 5d), but is not observed in unmated vab-1 female gonads (Fig. 5e). Unmated ceh-18(mg57) female gonads are weakly stained by MAPK-YT, but rarely in the most proximal oocytes (Fig. 5f). In contrast, the most proximal oocytes stain intensely when ceh-18(mg57) females are mated (Fig. 5g). MAPK activation in oocytes is not sperm-dependent in vab-1(RNAi); ceh-18(mg57) females or ceh-18(mg57);vab-1(dx31)/+ heterozygous females, because mating does not affect MAPK-YT staining (Fig. $5 h, i$; data not shown). However, we observed a qualitative reduction in the maximal MAPK-YT staining intensity of oocytes in ceh-18(mg57);vab-1(dx31)/+ heterozygous females relative to wild-type and vab-1(RNAi) ceh18(mg57) females (Fig. 5b,d,h,i), suggesting that high levels of MAPK activation are not necessary for high oocyte maturation rates. These results indicate that 

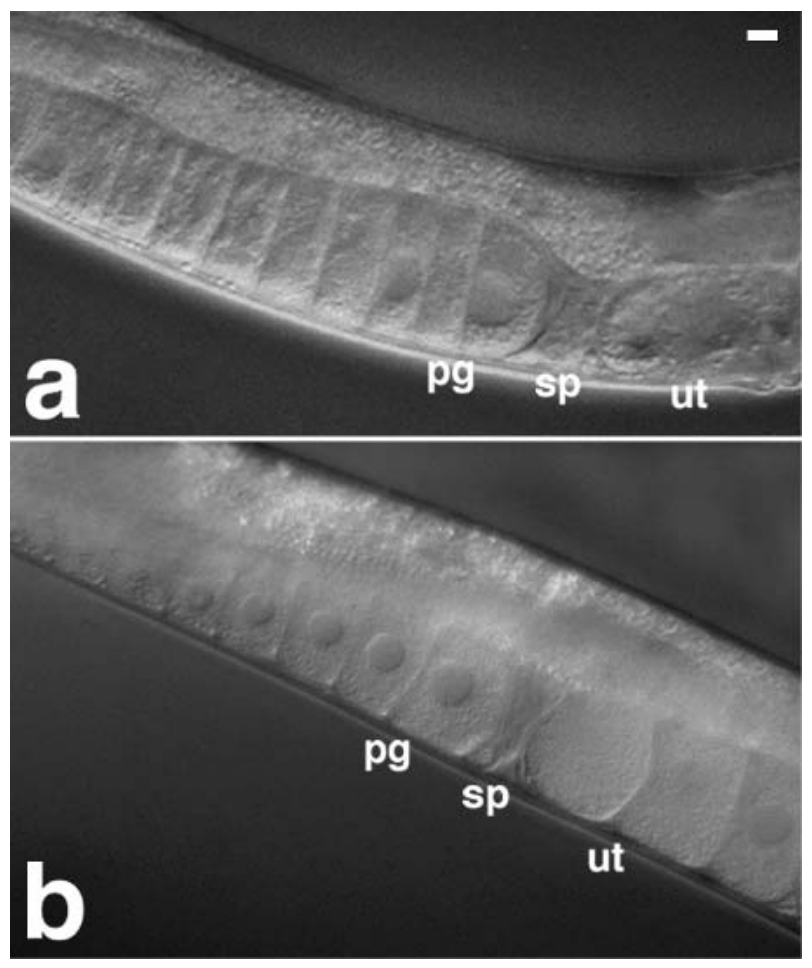

Figure 6. VAB-1 and CEH-18 inhibit oocyte meiotic maturation and ovulation. DIC micrographs of unmated fog-2(q71) $(a)$ and fog-2(q71);ceh-18(mg57); vab-1(RNAi) (b) females. (a) The oocyte maturation and ovulation rate is very low in unmated fog-2( $q 71)$ females (see Table 2 for rate measurements). Oocytes are arrested in meiotic prophase and accumulate in the proximal gonad arm (pg) until insemination occurs and sperm migrate to the spermatheca (sp). Unfertilized oocytes do not accumulate in the uterus (ut). (b) In contrast, the oocyte maturation and ovulation rates are high and independent of sperm in unmated fog-2(q71); ceh-18(mg57); vab-1(RNAi) females. Oocytes do not accumulate in the proximal gonad arm in these mutants. Instead, the uterus fills with unfertilized oocytes. Bar, $10 \mu$.

VAB-1 and a parallel signaling pathway(s), which is dependent on the sheath cell transcription factor CEH-18, negatively regulate oocyte MAPK activation.

\section{The ephrin efn-2 negatively regulates} oocyte maturation

Stimulation of mammalian EphA receptor kinase activity by ephrin-A1 inhibits the Ras/MAPK cascade in cultured cells (Elowe et al. 2001; Miao et al. 2001). The VAB-1 extracellular ephrin binding domain and intracellular kinase domain are necessary for the inhibition of oocyte maturation in C. elegans hermaphrodites and fog2(q71) females (Table 1, cf. lines 5-7 and 2; Table 2, cf. lines 17 and $8 ; P<0.001)$, suggesting that maturation may be negatively regulated by an interaction between VAB-1 and ephrins. The C. elegans genome contains four ephrins that bind VAB-1 (Chin-Sang et al. 1999; Wang et al. 1999). To determine whether ephrins negatively regulate maturation, we examined ephrin null mutant her- maphrodites (Chin-Sang et al. 1999; Wang et al. 1999). Although we did not detect oocyte maturation defects in vab-2(e96) (Table 1, cf. lines 8 and 2), efn-3(ev696), or efn-4(bx80) hermaphrodites (data not shown), efn2(ev658) hermaphrodites continue to lay unfertilized oocytes after sperm are depleted (Table 1, cf. lines 9 and 2). Also, efn-2(ev658) hermaphrodite gonads exhibit slightly enhanced MAPK-YT staining compared to wild-type hermaphrodite gonads (Fig. 5b,j). Analysis of efn-2(ev658) hermaphrodites indicates that they are defective in inhibiting oocyte maturation and ovulation when sperm numbers are low (<15 sperm per gonad arm) or sperm have been depleted. Consistent with this idea, efn2(ev658) hermaphrodites and efn-2(ev658);fog-2(q71) males produce functional sperm with wild-type morphology, although efn-2(ev658) hermaphrodites generate fewer sperm than the wild type. Unmated efn-2(ev658) and efn-2(ev658);ceh-18(mg57) females have significantly higher oocyte maturation rates than unmated females and ceh-18(mg57) females, respectively (Table 2, cf. lines 18 and 2, 19 and $8 ; P<0.001$ ). Additional VAB-1 ligands may be involved because the oocyte maturation rate in efn-2(ev658) null females is not as high as that in $v a b-1(d \times 31)$ null females. These results are consistent with the hypothesis that an interaction between EFN-2 and VAB-1 inhibits oocyte maturation.

VAB-1 is required for the MSP-mediated increase in the basal gonadal sheath cell contraction rate (Table 1, cf. lines 1-4). vab-1(e2) hermaphrodites exhibit a slight reduction in the basal contraction rate relative to the wild type, indicating that this response is largely independent of VAB-1 kinase activity (Table 1, cf. lines 2-5). To determine whether an ephrin/VAB-1 interaction is required for MSP-mediated contractions, we examined $v a b-1(j u 8), v a b-1(e 699), v a b-2(e 96)$, efn-2(ev658), efn3(ev696), and efn-4(bx80) mutant hermaphrodites. The sheath cell contraction rate in these strains is not significantly different than the wild-type rate (Table 1 , cf. lines 6-9 and 2; data not shown; $P>0.05)$. Therefore, MSP-mediated sheath cell contractions require VAB-1, but not ephrins.

\section{vab-1 functions in the germ line and somatic gonad}

VAB-1::GFP is expressed in oocytes and sheath cells in the juIs24 reporter strain (Fig. 4). Analysis of oocyte meiotic maturation and sheath cell contraction in these hermaphrodites indicates that this strain is rescued for defects observed in vab-1 loss-of-function alleles. To determine whether $v a b-1$ function is required in both germline and somatic cells of the gonad, we used rrf1(pk1417) mutants, which are sensitive to RNAi in the germ line, but resistant to RNAi in the soma (Sijen et al. 2001). vab-1 RNAi of wild-type hermaphrodites results in an impaired ability to inhibit oocyte maturation and ovulation following the depletion of self-derived sperm (Table 1, cf. lines 4 and 2). This function is required in the germ line, because $v a b-1$ (RNAi); rrf-1(pk1417) hermaphrodites lay significantly more unfertilized oocytes than $r r f-1$ (pk1417) hermaphrodites (Table 1, cf. lines 11 
and $10 ; P<0.001 \mid$. Similar results were obtained for efn2 , suggesting that it also functions in the germ line (Table 1, cf. lines 12 and 10; $P<0.001$ ). In these experiments, unfertilized oocytes are not observed until sperm are few in number $(<25$ per gonad arm) or have been depleted. These results support the hypothesis that EFN-2 and VAB-1 function in the hermaphrodite germ line to inhibit oocyte maturation and ovulation when the supply of self-derived sperm becomes low. To determine whether VAB-1 functions in the germ line of females that have never received MSP signals, we examined the oocyte maturation rate of unmated $v a b-1$ (RNAi); rrf-1(pk1417) fog-3(q443) females. The maturation rate of unmated vab-1 (RNAi); rrf-1(pk1417) fog3(q443) females is not significantly different than that of unmated vab-1 (RNAi); fog-3(q443) females, but is significantly different than those of unmated $\operatorname{rrf}-1(p k 1417)$ fog-3(q443) females (Table 2, cf. lines 20-22; $P<0.001$ ) and unmated fog-3(q443) females. Therefore, these results support the hypothesis that VAB-1 functions autonomously in oocytes to negatively regulate oocyte maturation and ovulation.

To determine whether VAB-1 is required in somatic sheath cells for modulating the contraction rate, we compared the contraction rates of vab-1 (RNAi); rrf1(pk1417) hermaphrodites to those of $r r f-1$ (pk1417) and $v a b-1$ (RNAi) hermaphrodites. These results indicate that VAB-1 is required in somatic cells for sheath contraction (Table 1, cf. lines 10,11 and 4; $P<0.001$ ). This is consistent with data of McCarter et al. (1999), who showed that the sperm-dependent increase in the basal sheath cell contraction rate requires sperm and sheath cells, but not oocytes. Therefore, the data support the hypothesis that an interaction between MSP and VAB-1 on sheath cell membranes modulates the basal sheath cell contraction rate.

\section{Discussion}

Oocytes prepare for fertilization and embryogenesis by a process called meiotic maturation, which is characterized by nuclear envelope breakdown (M-phase entry), cortical cytoskeletal rearrangement, MAPK activation, and meiotic spindle assembly. In this study, we describe the MSP signaling mechanism used to control oocyte meiotic maturation and ovulation in C. elegans. Our results, together with those of previous studies (McCarter et al. 1999; Miller et al. 2001), are consistent with the following model (Fig. 7a). Signaling by the VAB-1 Eph receptor and a CEH-18-dependent pathway(s) negatively regulate oocyte maturation and MAPK activation in hermaphrodite and female gonads. Sperm disrupt these inhibitory pathways by releasing MSP, which binds to VAB-1 and an unidentified receptor(s). Binding antagonizes both VAB-1- and CEH-18-dependent signaling, thereby promoting the resumption of meiosis, MAPK activation, and ovulation. In the absence of CEH-18, VAB1-mediated inhibition is dosage-sensitive, suggesting that small MSP-induced attenuations in signaling are sufficient to trigger a response. Eliminating VAB-1 and
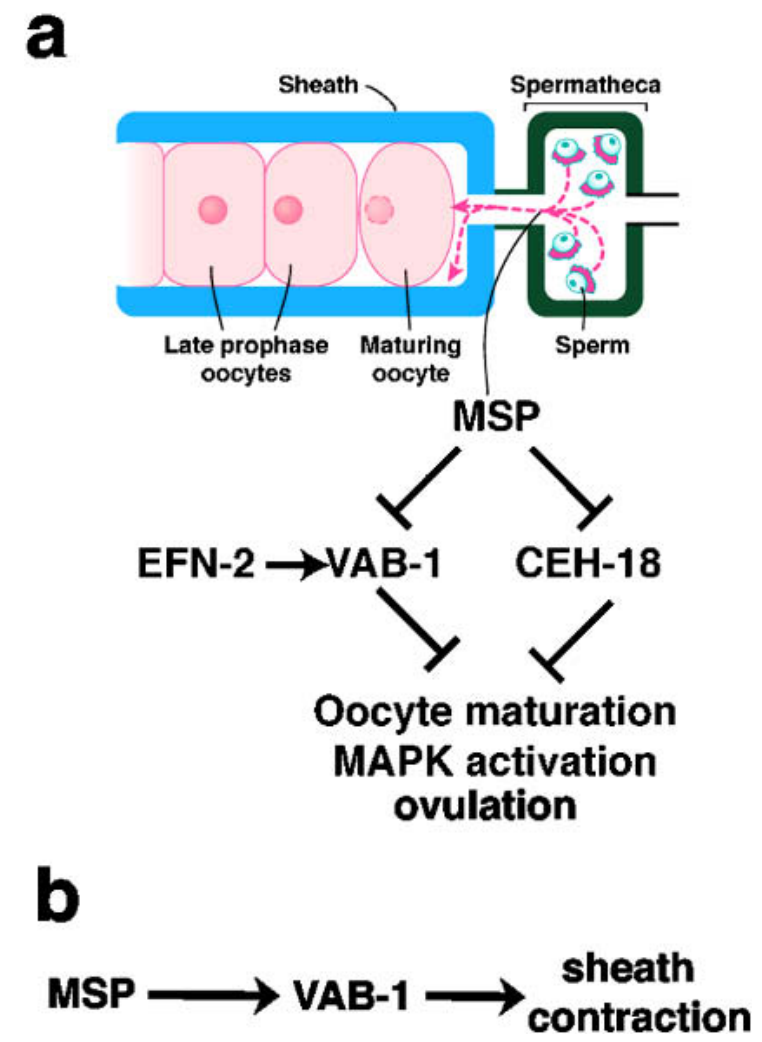

Figure 7. A sperm-sensing control mechanism regulates oocyte meiotic maturation and MAPK activation. (a) Sperm release MSP, which binds to VAB-1 and another receptor(s) on oocytes and sheath cells. MSP promotes oocyte M-phase entry (maturation), MAPK activation, and ovulation by antagonizing ephrin/Eph receptor (EFN-2/VAB-1) and sheath cell-dependent (CEH-18) inhibitory circuits (see Discussion for details; drawing modified with permission from Villeneuve 2001). (b) In sheath cells, MSP stimulates the basal contraction rate by acting as a VAB-1 agonist.

CEH-18 function removes the dependence of meiotic maturation and ovulation on the presence of sperm. Therefore, this meiotic control mechanism resembles a cell-cycle checkpoint (Hartwell and Weinert 1989) and may confer a selective advantage to hermaphrodites and females by conserving metabolically costly oocytes when sperm are unavailable for fertilization.

As in other animals, positive regulators of oocyte meiotic maturation have been identified in C. elegans, including the cyclin-dependent kinase homolog CDK-1 (Boxem et al. 1999) and the polo-like kinase homolog PLK-1 (Chase et al. 2000). In addition, the zinc finger domain-containing proteins OMA-1 and OMA-2 are redundantly required for oocyte maturation and ovulation (Detwiler et al. 2001). MSP signals are apparently received in oma-1(te33); oma-2(te51) mutant oocytes, but MAPK activation is not sustained and nuclear envelope breakdown does not occur. OMA-1 and OMA-2 may function upstream of two conserved cell-cycle regulators, the MYT1-related kinase WEE-1.3 and CDK-1 (Detwiler et al. 2001). Therefore, MSP signals are likely trans- 
mitted through a complex hierarchy of negative and positive intracellular regulators, which together comprise a sperm-sensing control mechanism.

Our results support the hypothesis that VAB-1-dependent pathways function in both oocytes and sheath cells (Fig. 7a,b). VAB-1 and EFN-2 are required in the germ line for the inhibition of oocyte maturation and ovulation. In somatic sheath cells, VAB-1 is required for MSP-mediated contractions (Fig. $7 \mathrm{~b}$ ). Ephrins are not required for this response, which is consistent with data indicating that MSP-FITC binding and the sheath contraction rate (Table 1) are not affected in ephrin ligand binding domain mutants vab-1(ju8) and vab-1(e699) (Fig. 3b). Therefore, VAB-1 has an ephrin-dependent function in the germ line and an ephrin-independent function in sheath cells. We showed previously that the C-terminal 21 amino acids of MSP are sufficient to promote sheath contraction (Miller et al. 2001). Preincubation of gonads with a 25-fold molar excess of this C-terminal peptide does not reduce MSP-FITC binding, suggesting that the contribution of this domain to total binding is minimal (M. Miller and D. Greenstein, unpubl.). We currently favor the hypothesis that the MSP C-terminal domain functions by modulating an interaction between VAB-1 and another protein, possibly a channel. More comprehensive structure and function relationships will be possible when other MSP signaling mediators are identified.

Soma-germline interactions and the control of meiotic maturation and ovulation

The smooth muscle-like sheath cells surrounding the oocytes play a complex role in regulating meiotic maturation and ovulation. Sheath cells contract to facilitate ovulation, but also negatively regulate maturation and ovulation in the absence of MSP. ceh-18 is expressed in the sheath cells, but not in the oocytes (Greenstein et al. 1994), and is required for normal sheath cell differentiation and function (Rose et al. 1997). CEH-18 may directly regulate MSP-responsive components needed to establish or maintain inhibition. Alternatively, ceh-18 mutations may alter differentiated sheath cell features that directly or indirectly impair signaling to oocytes. For example, signaling through gap junctions could negatively regulate maturation. Gap junctions are observed between sheath cells and oocytes in wild-type gonads (Hall et al. 1999). In contrast, transmission electron microscopy reveals that ceh-18 mutant sheath cells are not closely apposed to oocytes and sheath/oocyte gap junctions are rare or absent (Rose et al. 1997). In mammals, the somatic cumulus cells surrounding the oocytes are thought to negatively regulate meiotic maturation, possibly by signaling through gap junctions (for review, see Wickramasinghe and Albertini 1993). cAMP has been proposed to mediate this inhibition by diffusing from cumulus cells to oocytes through these junctions (Webb et al. 2002). Studies in Xenopus and starfish do not support a role for somatic gonadal cells in inhibiting meiotic maturation. However, several Xenopus signaling pro- teins have been identified that negatively regulate MPF (CD1/cyclin B) activation, including cAMP-dependent protein kinase A and p21-activated kinase (Maller and Krebs 1977; Faure et al. 1999). Thus, the extent to which the signaling mechanisms regulating meiotic maturation are conserved among animals with different reproductive strategies is still not clear. However, the similarities in the regulatory features shared by C. elegans and mammalian species are provocative.

\section{Eph receptors as negative regulators of MAPK activation and cell-cycle progression}

Many receptor protein-tyrosine kinases (RPTKs), such as the epidermal growth factor receptor and insulin receptor, transmit signals through a canonical pathway that stimulates MAPK activation and cell-cycle progression (for review, see van der Geer et al. 1994). One exception to this rule is the Eph receptors, which comprise the largest family of RPTKs in vertebrates (for review, see Klein 2001). Activation of mammalian Eph receptors by their ephrin ligands down-regulates the Ras/MAPK cascade in cultured cells (Elowe et al. 2001; Miao et al. 2001) and inhibits proliferation in vivo (Conover et al. 2000). We show that VAB-1, the only Eph receptor in C. elegans, negatively regulates oocyte $M$-phase entry and MAPK activation. This inhibitory mechanism requires the VAB-1 catalytic domain, the ephrin EFN-2, and a parallel signaling pathway(s) defined by the homeoprotein ceh-18. Our studies, together with those in mammals, suggest that the negative regulation of MAPK activation and cell-cycle progression is an ancestral feature of ephrin/Eph receptor signal transduction. Antagonistic Eph receptor ligands, like MSP, may mediate the mitogenic effects commonly seen with ligands for other RPTKs.

\section{MSP domain proteins and signal transduction}

The primary structure of the MSP immunoglobulin-like fold (Bullock et al. 1996) has been conserved throughout eukaryotic evolution. Proteins with MSP domains fall into soluble and membrane-spanning classes (Miller et al. 2001). Members of the membrane-spanning class are collectively referred to as the VAPs /vesicle-associated membrane protein-associated proteins), which are type II integral membrane proteins. Although studies of the soluble members have been limited to nematodes, the VAPs have been characterized in yeast (Kagiwada et al. 1998), plants (Laurent et al. 2000), Drosophila (Pennetta et al. 2002), Aplysia (Skehel et al. 1995), and mammals (Nishimura et al. 1999; Skehel et al. 2000). However, their biochemical functions are not well defined and they have been localized to a variety of subcellular compartments, including the endoplasmic reticulum (ER), Golgi network, and plasma membrane.

In C. elegans, the MSPs comprise a large multigene family of soluble, sperm-specific proteins. Within the MSP domain are sequences that mediate extracellular 
VAB-1 and CEH-18 regulate oocyte meiotic maturation

signaling (Miller et al. 2001) and intracellular cytoskeletal functions (for review, see Bottino et al. 2002). One possibility is that these are ancestral functions shared with some of the membrane-spanning VAPs. Alternatively, these may be novel functions acquired during the evolution of the nematode reproductive system. We show that MSP signals oocyte maturation and MAPK activation by transmitting signals through multiple receptors, including the VAB-1 Eph receptor. An Eph receptor homolog has been found in the sponge Ephydatia fluviatilis (Suga et al. 2001), placing these RPTKs with the MSP domain in the earliest metazoans. In Drosophila, mutations in two VAPs have been isolated; farinelli was localized to the sperm plasma membrane and is required for male fertility (accession no. AF280798). DVAP-33A is broadly expressed and has a role in bouton formation at the neuromuscular junction (Pennetta et al. 2002). Genetic analysis indicates that DVAP-33A functions as a dosage-dependent instructive signal for bouton number and size. Although DVAP-33A predominantly localizes to intracellular membranes, some protein is found at the plasma membrane. The presence of VAPs at synapses (Skehel et al. 1995; Pennetta et al. 2002) is interesting because Eph receptors have been localized to neurons and synapses in many animals (for review, see Klein 2001). Therefore, it is possible that MSP domain-containing proteins function in an extracellular signaling capacity in other animals.

\section{Evolution of nematode reproduction}

Species in highly competitive, dynamic environments require robust reproductive mechanisms that efficiently turn nutritional resources into viable offspring. Three reproductive modes are utilized in the Nematoda. The most common is the gonochoristic mode (male/female), where reproduction occurs exclusively by out-crossing. Hermaphroditic species reproduce by selfing, although out-cross progeny are possible in facultative hermaphrodites (male/hermaphrodite) such as C. elegans. Parthenogenetic species also reproduce by selfing, but in the absence of sperm altogether. Phylogenetic analysis suggests that both hermaphroditic and parthenogenetic reproductive modes have been repeatedly derived in nematodes, and that gonochorism represents the ancestral mode (Blaxter et al. 1998; Fitch 2000). MSP is highly conserved in diverse nematodes. C. elegans MSP promotes oocyte maturation and ovulation in its gonochoristic sister species, C. remanei (Miller et al. 2001), and MSP from the pig parasite Ascaris suum promotes maturation and ovulation in C. elegans (M. Kosinski and D. Greenstein, unpubl.). Therefore, $\mathrm{MSP}^{\prime}$ s role as a reproductive signal likely evolved in gonochoristic nematodes or their ancestors and has been conserved in facultative hermaphrodites like C. elegans. The sperm-sensing control mechanism described here may confer a strong selective advantage to gonochoristic and hermaphroditic nematode species by enhancing their reproductive efficiency.

\section{Materials and methods}

\section{C. elegans genetics and strains}

Culture and genetic manipulations of C. elegans strains were carried out (Brenner 1974) at $20^{\circ} \mathrm{C}$ except where indicated otherwise. All fog-2(q71)V (Schedl and Kimble 1988) strains were maintained as male/female stocks. vab-1 alleles (George et al. 1998) were maintained as homozygous strains or were balanced in male/female stocks using the inversion $\operatorname{mIn} 1$ [dpy-10(e128) mIs14(myo-2::gfp + pes-10::gfp)]II (Edgley and Riddle 2001), which is dominantly marked with $g f p$. The strains and genetic markers used or generated were as follows: DG620 [unc-13(e51) fog-3(q443)/hT2I] (Ellis and Kimble 1995), PD8488 [rrf1(pk1417)I], DG1743 [fog-3(q443)/hT2(qIs48)I], DG1744 [rrf1(pk1417) fog-3(q443)/hT2(qIs48)I], CB2 [vab-1(e2)]II, CZ337 [vab-1(dx31)II], CZ414 [vab-1(e699)II], CZ479 [vab-1(ju8)II], DG1610 [vab-1(e2)/mIn1II; fog-2(q71)V], DG1612 [vab1(dx31)/mIn1II; fog-2(q71)V], DG1635 [vab-1(e2)/mIn1II; fog2(q71)V; ceh-18(mg57)X], DG1650 [vab-1(dx31)/mIn1II; fog2(q71)V; ceh-18(mg57)X], DG1669 [vab-1(e699)/mIn1II; fog2(q71)V; ceh-18(mg57)X], CZ793 \{vab-1(e2027)II; lin15(n765ts)X; juIs24[vab-1::gfp + lin-15(+)]], cam-1(gm105 and gm122)II (Forrester et al. 1999), DG1695 [cam-1(gm122)/ mIn1II; fog-2(q71)V], DG1696 [cam-1(gm105)/mIn1II; fog2(q71)V], CZ1743[efn-2(ev658)IV] (Wang et al. 1999), DG1633 [efn-2(ev658)IV; fog-2(q71)V], DG1647 [efn-2(ev658)IV, fog2(q71)V; ceh-18(mg57)X], BS980 [unc-24(e138) fem-3(e1996)/ nT1IV; emo-1(oz1)/nT1V] (Iwasaki et al. 1996), BS939 [emo1(oz1)/DnT1V], WM43 [gex-3(zu196)/DnT1IV] (Soto et al. 2002), DH1390 [rme-2(b1008)IV] (Grant and Hirsh 1999), DG1621 [cav-1(ok270)IV], DG1623 [tsp-12(T14G10.6ok239)IV], CB96 [vab-2(e96)IV], EM305 [efn-4(bx80)IV; him-5(e1490)], DG1737 [lip-1(zh15)IV; fog-2(q71)V], CB4108 [fog-2(q71)V], DG1604 [fog-2(q71)V; ceh-18(mg57)X], NW1389 [efn3(ev696)X] (Wang et al. 1999), and GR1034 [ceh-18(mg57)X] (Greenstein et al. 1994).

For marker scoring, ceh-18(mg57)X was scored by gonadal phenotype and by PCR. efn-2(ev658)IV was scored using the highly penetrant L1-stage head tip defect. $\operatorname{mIn} 1$ was scored using its recessive Dumpy (homozygotes) and dominant Green (heterozygotes) phenotypes. vab-1 mutants $(d x 31, e 2, e 699$, and ju8) were scored using the notched-head phenotype and/or by the absence of a Green phenotype in the progeny of $m \operatorname{In} 1$-bearing parents. $r r f-1$ (pk1417) was scored by PCR (Sijen et al. 2001). Maturation rates in $r r f-1$ (pk1417); fog-3(q443) females were not significantly different than fog-3(q443) females.

To construct strains of genotype $v a b-1(x) / \mathrm{mIn} 1 I I$; fog2(q71)V, fog-2(q71) males were crossed to vab-1(x) hermaphrodites. The F1 males were then crossed to $m I n 1$ hermaphrodites, and cross-progeny were cultured individually. Females of genotype $v a b-1(x) / m I n 1 ; f o g-2(q 71)$ were recovered and crossed to fog-2(q71) males. In the next generation, a series of single male/ female matings were set up in which the female had a nonGreen phenotype and the male had a Green phenotype $(m \operatorname{In} 1 /+)$, as assessed using a dissecting microscope equipped with indirect fluorescence illumination optics. A final series of single male/ female matings were set up in which both mating partners had a Green phenotype. From these matings, balanced vab-1(x)/ mIn1;fog-2(q71) male/female stocks were recovered.

To construct strains of genotype vab-1(x)/mIn1II;fog2(q71)V;ceh-18(mg57)X,vab-1(x)/mIn1;fog-2(q71) males were crossed to fog-2(q71);ceh-18(mg57) females. The F1 ceh18(mg57) hemizygous males were crossed to fog-2(q71);ceh18(mg57) females. From these crosses, a series of single male/ female matings were set up in which the female had a nonGreen 
phenotype and the male had a Green phenotype. A final series of single male/female matings were set up in which both mating partners had a Green phenotype in order to recover vab-1(x)/ mIn1;fog-2(q71)V;ceh-18(mg57)X balanced male/female stocks.

\section{Phenotypic analysis and cell biology}

Standard protocols for analyzing oocyte meiotic maturation, sheath contraction, and MAPK activation were used (Miller et al. 2001). MAPK experiments were repeated two or more times using 50-100 dissected gonads per experiment. Representative images are shown. Gonadal sheath cell contraction rates were determined from time-lapse video recordings prepared at room temperature $\left(23^{\circ} \mathrm{C}\right)$. Oocyte meiotic maturation rates were determined by monitoring total ovulations in $1-4$-h time periods. Sheath contraction rates and oocyte meiotic maturation rates were scored in animals $24-48 \mathrm{~h}$ after the mid-L4 stage. The microinjection of MSP and MSP-FITC into unmated fog-2(q71) females was described (Miller et al. 2001). RNAi was performed in L4 and adult hermaphrodites using the feeding method (Kamath et al. 2001). The number of fertilized eggs and unfertilized oocytes laid on plates was determined during a 7-d time course. $v a b-1$ mutant hermaphrodites that died or those with egg-laying defects were not scored. The uterus of old vab-1 mutant hermaphrodites frequently clogs with unfertilized oocytes, which we were unable to count. Incompletely penetrant gonadal defects are observed in vab-1 and vab-1; ceh-18 mutants, including the depletion of oocytes from the gonad and defective ovulation. These defects typically occur in less than $20 \%$ of animals, which were not used for quantitating maturation rates. Misshapen oocytes are observed more frequently. Oocytes are occasionally small or missing (less than $20 \%$ of animals) in adult efn-2(ev658);ceh-18(mg57) female gonad arms. These animals appear to ovulate oocytes faster than they generate them and were not used for quantitation. We analyzed lip-1(zh15); fog-2(q71) females as a control because a recent report suggested that lip-1 is necessary for oocytes to arrest or maintain arrest at diakinesis (Hajnal and Berset 2002). We observed that oocytes in lip-1(zh15); fog-2(q71) females stacked in the gonad arm and did not undergo maturation and ovulation at elevated rates $(M$. Miller and D. Greenstein, unpubl.).

\section{Receptor binding}

MSP-6His was purified from E. coli (Miller et al. 2001) and labeled with NHS-Fluorescein (Pierce) at $23^{\circ} \mathrm{C}$ in the dark for 1-4 $\mathrm{h}$, according to the manufacturer's instructions. An excellulose desalting column (Pierce) was used to remove unreacted NHSFluorescein. Gonads were dissected in egg-salts solution (118 $\mathrm{mM} \mathrm{NaCl}, 48 \mathrm{mM} \mathrm{KCl}$ ) and incubated with $200 \mu \mathrm{L}$ MSP-FITC for $20 \mathrm{~min}$. Gonads were then washed three times with $200 \mu \mathrm{L}$ or once with $1 \mathrm{~mL}$ egg-salts, fixed in $1 \%$ paraformaldehyde for $5 \mathrm{~min}$, and mounted. MSP binding was quantified on an Axiovert 200M photomicroscope (Zeiss) equipped with an Orca ER (Hamamatsu) charge-coupled device camera. Average pixel intensity was measured in arbitrary fluorescent units from linearrange exposures using MetaMorph software (Universal Imaging). A $25 \mu^{2}$ region from the two most proximal oocytes of the gonad arm was used for quantitation. Binding was measured by subtracting nonspecific binding from specific binding to oocytes. Each binding experiment was performed with and compared to a parallel control group. COS-7 cells were transfected with 2-6 $\mu \mathrm{g}$ of VAB-1 or Src control plasmids as described (Ruest et al. 2001). Cells were grown on coverslips, incubated in 100$200 \mathrm{nM}$ MSP-FITC, washed with $50 \mathrm{~mL}$ phosphate-buffered saline, and mounted.

\section{$V A B-1:: G F P$ expression}

The rescuing VAB-1::GFP transgenic reporter juIs24 was visualized using an Axiovert 200M photomicroscope equipped with a Orca ER charge-coupled device camera. For detection, gonads were dissected, fixed for $10 \mathrm{~min}$ in $50 \%$ ethanol, and mounted. To eliminate background fluorescence in oocytes, animals were incubated in egg-salts solution for $3 \mathrm{~h}$ prior to dissection. Axial scans were performed on wild-type and juIs24 gonads using step sizes of approximately one micron. We used AutoDeblur (AutoQuant Imaging), the Blind Deconvolution software application, to remove out-of-focus haze and blur from these 3D micrographs. With this method, VAB-1::GFP is detectable in $25 \%-50 \%$ of dissected gonads. However, rescue of $v a b-1(0)$ oocyte and sheath cell defects was observed in all juIs24 hermaphrodites examined $(\mathrm{n}>25)$.

\section{Acknowledgments}

This paper is dedicated to the memory of Howard H. Andrews. We thank A. Chisholm, B. Barstead, J. Culotti, W. Forrester, B. Grant, J. Kimble, T. Schedl, M. Vidal, and X. Wang for strains and reagents; Y. Kohara for sharing unpublished in situ hybridization data; and Rob Steele, Brigid Hogan, and David Miller for helpful discussions and comments. Special thanks to T. Schedl for suggesting the rrf-1 experiments and two anonymous reviewers for providing helpful comments. Some strains were provided by the Caenorhabditis Genetics Center. This work was supported by NIH grants to D.G. (GM57173 and GM65115) and S.K.H. (GM49882), a VICC center support grant (P30CA68485), an American Cancer Society postdoctoral research fellowship to M.A.M., and NIH Training Grant T32 CA09592 to M.K.

The publication costs of this article were defrayed in part by payment of page charges. This article must therefore be hereby marked "advertisement" in accordance with 18 USC section 1734 solely to indicate this fact.

\section{References}

Austin, J. and Kimble, J. 1987. glp-1 is required in the germ line for regulation of the decision between mitosis and meiosis in C. elegans. Cell 51: 589-599.

Blaxter, M.L., De Ley, P., Garey, J.R., Liu, L.X., Scheldeman, P., Vierstraete, A., Vanfleteren, J.R., Mackey, L.Y., Dorris, M., Frisse, L.M., et al. 1998. A molecular evolutionary framework for the phylum Nematoda. Nature 392: 71-75.

Bottino, D., Mogilner, A., Roberts, T., Stewart, M., and Oster, G. 2002. How nematode sperm crawl. J. Cell Sci. 115: 367-384

Boxem, M., Srinivasan, D.G., and van den Heuvel, S. 1999. The Caenorhabditis elegans gene ncc-1 encodes a CDC2-related kinase required for $M$ phase in meiotic and mitotic cell divisions, but not for S phase. Development 126: 2227-2239.

Brenner, S. 1974. The genetics of Caenorhabiditis elegans. Genetics 77: 71-94.

Bullock, T.L., Roberts, T.M., and Stewart, M. 1996. 2.5 Å resolution crystal structure of the motile major sperm protein (MSP) of Ascaris suum. J. Mol. Biol. 263: 284-296.

Chase, D., Serafinas, C., Ashcroft, N., Kosinski, M., Longo, D., Ferris, D.K., and Golden, A. 2000. The polo-like kinase PLK-1 is required for nuclear envelope breakdown and the completion of meiosis in Caenorhabditis elegans. Genesis 26: $26-41$.

Chin-Sang, I.D., George, S.E., Ding, M., Moseley, S.L., Lynch, A.S., and Chisholm, A.D. 1999. The ephrin VAB-2/EFN-1 
functions in neuronal signaling to regulate epidermal morphogenesis in C. elegans. Cell 99: 781-790.

Church, D.L., Guan, K.L., and Lambie, E.J. 1995. Three genes of the MAP kinase cascade, mek-2, mpk-1/sur-1 and let-60 ras, are required for meiotic cell cycle progression in Caenorhabditis elegans. Development 121: 2525-2535.

Conover, J.C., Doetsch, F., Garcia-Verdugo, J.M., Gale, N.W., Yancopoulos, G.D., and Alvarez-Buylla, A. 2000. Disruption of Eph/ephrin signaling affects migration and proliferation in the adult subventricular zone. Nat. Neurosci. 3: 1091-1097.

Crittenden, S.L., Troemel, E.R., Evans, T.C., and Kimble, J. 1994. GLP-1 is localized to the mitotic region of the C. elegans germ line. Development 120: 2901-2911.

Detwiler, M.R., Reuben, M., Li, X., Rogers, E., and Lin, R. 2001. Two zinc finger proteins, OMA-1 and OMA-2, are redundantly required for oocyte maturation in C. elegans. Dev. Cell 1: 187-199.

Edgley, M.L. and Riddle, D.L. 2001. LG II balancer chromosomes in Caenorhabditis elegans: $m T 1(I I ; I I I)$ and the $m I n 1$ set of dominantly and recessively marked inversions. Mol. Genet. Genomics 266: 385-395.

Edwards, R.G. 1965. Maturation in vitro of mouse, sheep, cow, pig, rhesus monkey and human ovarian oocytes. Nature 208: 349-351.

Ellis, R.E. and Kimble, J. 1995. The fog-3 gene and regulation of cell fate in the germ line of Caenorhabditis elegans. Genetics 139: 561-577.

Elowe, S., Holland, S.J., Kulkarni, S., and Pawson, T. 2001. Downregulation of the Ras-mitogen-activated protein kinase pathway by the EphB2 receptor tyrosine kinase is required for ephrin-induced neurite retraction. Mol. Cell. Biol. 21: 7429-7441.

Faure, S., Vigneron, S., Galas, S., Brassac, T., Delsert, C., and Morin, N. 1999. Control of G2/M transition in Xenopus by a member of the p21-activated kinase (PAK) family: A link between protein kinase A and PAK signaling pathways? J. Biol. Chem. 274: 3573-3579.

Ferrell Jr., J.E. 1999. Xenopus oocyte maturation: New lessons from a good egg. Bioessays 21: 833-842.

Fitch, D.H. 2000. Evolution of Rhabditidae and the male tail. J. Nematol. 32: 235-244.

Forrester, W.C., Dell, M., Perens, E., and Garriga, G. 1999. A C. elegans Ror receptor tyrosine kinase regulates cell motility and asymmetric cell division. Nature 400: 881-885.

George, S.E., Simokat, K., Hardin, J., and Chisholm, A.D. 1998. The VAB-1 Eph receptor tyrosine kinase functions in neural and epithelial morphogenesis in C. elegans. Cell 92: 633643.

Grant, B. and Hirsh, D. 1999. Receptor-mediated endocytosis in the Caenorhabditis elegans oocyte. Mol. Biol. Cell 10: 43114326.

Greenstein, D., Hird, S., Plasterk, R.H., Andachi, Y., Kohara, Y., Wang, B., Finney, M., and Ruvkun, G. 1994. Targeted mutations in the Caenorhabditis elegans POU homeo box gene ceh- 18 cause defects in oocyte cell cycle arrest, gonad migration, and epidermal differentiation. Genes \& Dev. 8: 1935-1948.

Hajnal, A. and Berset, T. 2002. The C. elegans MAPK phosphatase LIP-1 is required for the G2/M meiotic arrest of developing oocytes. EMBO J. 21: 4317-4326.

Hall, D.H., Winfrey, V.P., Blaeuer, G., Hoffman, L.H., Furuta, T., Rose, K.L., Hobert, O., and Greenstein, D. 1999. Ultrastructural features of the adult hermaphrodite gonad of Caenorhabditis elegans: Relations between the germ line and soma. Dev. Biol. 212: 101-123.

Hartwell, L.H. and Weinert, T.A. 1989. Checkpoints: Controls that ensure the order of cell cycle events. Science 246: 629634.

Hsu, V., Zobel, C.L., Lambie, E.J., Schedl, T., and Kornfeld, K. 2002. Caenorhabditis elegans lin-45 raf is essential for larval viability, fertility and the induction of vulval cell fates. $G e$ netics 160: 481-492.

Hubbard, E.J. and Greenstein, D. 2000. The Caenorhabditis elegans gonad: A test tube for cell and developmental biology. Dev. Dyn. 218: 2-22.

Hunt, P.A. and LeMaire-Adkins, R. 1998. Genetic control of mammalian female meiosis. Curr. Top. Dev. Biol. 37: 359381.

Iwasaki, K., McCarter, J., Francis, R., and Schedl, T. 1996. emo1, a Caenorhabditis elegans Sec61p gamma homologue, is required for oocyte development and ovulation. J. Cell. Biol. 134: 699-714.

Jacobs, P.A. 1992. The chromosome complement of human gametes. Oxf. Rev. Reprod. Biol. 14: 47-72.

Kagiwada, S., Hosaka, K., Murata, M., Nikawa, J., and Takatsuki, A. 1998. The Saccharomyces cerevisiae SCS2 gene product, a homolog of a synaptobrevin-associated protein, is an integral membrane protein of the endoplasmic reticulum and is required for inositol metabolism. J. Bacteriol. 180: 1700-1708.

Kamath, R.S., Martinez-Campos, M., Zipperlen, P., Fraser, A.G., and Ahringer, J. 2001. Effectiveness of specific RNA-mediated interference through ingested double-stranded RNA in Caenorhabditis elegans. Genome Biol. 2: 1-10.

Klass, M.R. and Hirsh, D. 1981. Sperm isolation and biochemical analysis of the major sperm protein from C. elegans. Dev. Biol. 84: 299-312.

Klein, R. 2001. Excitatory Eph receptors and adhesive ephrin ligands. Curr. Opin. Cell Biol. 13: 196-203.

Kokel, M., Borland, C.Z., DeLong, L., Horvitz, H.R., and Stern, M.J. 1998. clr-1 encodes a receptor tyrosine phosphatase that negatively regulates an FGF receptor signaling pathway in Caenorhabditis elegans. Genes \& Dev. 12: 1425-1437.

Laurent, F., Labesse, G., and de Wit, P. 2000. Molecular cloning and partial characterization of a plant VAP33 homologue with a major sperm protein domain. Biochem. Biophys. Res. Commun. 270: 286-292.

Maller, J. and Krebs, E. 1977. Progesterone-stimulated induction of meiotic cell division in Xenopus oocytes. Induction by regulatory subunit and inhibition by catalytic subunit of adenosine $3^{\prime}: 5^{\prime}$-monophosphate-dependent protein kinase. $J$. Biol. Chem. 252: 1712-1718.

Masui, Y. 1985. Meiotic arrest in animal oocytes. In Biology of fertilization (eds. A. Monroy and C.B. Metz), Vol. 1, pp. 189219. Academic Press, Orlando, FL.

2001. From oocyte maturation to the in vitro cell cycle: The history of discoveries of maturation-promoting Factor (MPF) and cytostatic factor (CSF). Differentiation 69: 1-17.

McCarter, J., Bartlett, B., Dang, T., and Schedl, T. 1999. On the control of oocyte meiotic maturation and ovulation in Caenorhabditis elegans. Dev. Biol. 205: 111-128.

Miao, H., Wei, B.R., Peehl, D.M., Li, Q., Alexandrou, T., Schelling, J.R., Rhim, J.S., Sedor, J.R., Burnett, E., and Wang, B. 2001. Activation of EphA receptor tyrosine kinase inhibits the Ras/MAPK pathway. Nat. Cell Biol. 3: 527-530.

Miller, M.A., Nguyen, V.Q., Lee, M.H., Kosinski, M., Schedl, T., Caprioli, R.M., and Greenstein, D. 2001. A sperm cytoskeletal protein that signals oocyte meiotic maturation and ovulation. Science 291: 2144-2147.

Nishimura, Y., Hayashi, M., Inada, H., and Tanaka, T. 1999. Molecular cloning and characterization of mammalian homologues of vesicle-associated membrane protein-associ- 
ated (VAMP-associated) proteins. Biochem. Biophys. Res. Commun. 254: 21-26.

Page, B.D., Guedes, S., Waring, D., and Priess, J.R. 2001. The $C$. elegans E2F- and DP-related proteins are required for embryonic asymmetry and negatively regulate Ras/MAPK signaling. Mol. Cell 7: 451-460.

Pennetta, G., Hiesinger, P., Fabian-Fine, R., Meinertzhagen, I., and Bellen, H.J. 2002. Drosophila VAP-33A directs bouton formation at neuromuscular junctions in a dosage-dependent manner. Neuron 32: 291-306.

Pincus, G. and Enzmann, E.V. 1935. The comparative behaviour of mammalian eggs in vivo and in vitro. J. Exp. Med. 62: 655675.

Reinke, V., Smith, H.E., Nance, J., Wang, J., Van Doren, C., Begley, R., Jones, S.J., Davis, E.B., Scherer, S., Ward, S., et al. 2000. A global profile of germline gene expression in C. elegans. Mol. Cell 6: 605-616.

Rose, K.L., Winfrey, V.P., Hoffman, L.H., Hall, D.H., Furuta, T., and Greenstein, D. 1997. The POU gene ceh-18 promotes gonadal sheath cell differentiation and function required for meiotic maturation and ovulation in Caenorhabditis elegans. Dev. Biol. 192: 59-77.

Ruest, P.J., Shin, N.Y., Polte, T.R., Zhang, X., and Hanks, S.K. 2001. Mechanisms of CAS substrate domain tyrosine phosphorylation by FAK and Src. Mol. Cell Biol. 21: 76417652.

Runft, L.L., Jaffe, L.A., and Mehlmann, L.M. 2002. Egg activation at fertilization: Where it all begins. Dev. Biol. 245: 237254.

Schedl, T. and Kimble, J. 1988. fog-2, a germ-line-specific sex determination gene required for hermaphrodite spermatogenesis in Caenorhabditis elegans. Genetics 119: 43-61.

Scheel, J., Srinivasan, J., Honnert, U., Henske, A., and Kurzchalia, T.V. 1999. Involvement of caveolin-1 in meiotic cellcycle progression in Caenorhabditis elegans. Nat. Cell Biol. 1: 127-129.

Sijen, T., Fleenor, J., Simmer, F., Thijssen, K., Parrish, S., Timmons, L., Plasterk, R., and Fire A. 2001. On the role of RNA amplification in dsRNA-triggered gene silencing. Cell 107: 465-476.

Skehel, P.A., Martin, K.C., Kandel, E.R., and Bartsch, D. 1995. A VAMP-binding protein from Aplysia required for neurotransmitter release. Science 269: 1580-1583.

Skehel, P.A., Fabian-Fine, R., and Kandel, E.R. 2000. Mouse VAP33 is associated with the endoplasmic reticulum and microtubules. Proc. Nat1. Acad. Sci. 97: 1101-1116.

Soto, M.C., Qadota, H., Kasuya, K., Inoue, M., Tsuboi, D., Mello, C.C., and Kaibuchi, K. 2002. The GEX-2 and GEX-3 proteins are required for tissue morphogenesis and cell migrations in C. elegans. Genes \& Dev. 16: 620-632.

Suga, H., Katoh, K., and Miyata, T. 2001. Sponge homologs of vertebrate protein tyrosine kinases and frequent domain shufflings in the early evolution of animals before the parazoan-eumetazoan split. Gene 280: 195-201.

van der Geer, P., Hunter, T., and Lindberg, R.A. 1994. Receptor protein-tyrosine kinases and their signal transduction pathways. Annu. Rev. Cell Biol. 10: 251-337.

Villeneuve, A.M. 2001. How to stimulate your partner. Science 291: 2099-2101.

Wang, X., Roy, P.J., Holland, S.J., Zhang, L.W., Culotti, J.G., and Pawson, T. 1999. Multiple ephrins control cell organization in C. elegans using kinase-dependent and -independent functions of the VAB-1 Eph receptor. Mol Cell. 4: 903-913.

Ward, S. and Carrel, J.S. 1979. Fertilization and sperm competition in the nematode Caenorhabditis elegans. Dev. Biol. 73: 304-321.
Webb, R.J., Marshall, F., Swann, K., and Carroll, J. 2002. Folliclestimulating hormone induces a gap junction-dependent dynamic change in [cAMP] and protein kinase $\mathrm{A}$ in mammalian oocytes. Dev. Biol. 246: 441-454.

Wickramasinghe, D. and Albertini, D. F. 1993. Cell cycle control during mammalian oogenesis. Curr. Top. Dev. Biol. 28: $125-153$.

Yochem, J. and Greenwald, I. 1989. glp-1 and lin-12, genes implicated in distinct cell-cell interactions in C. elegans, encode similar transmembrane proteins. Cell 58: 553-563. 


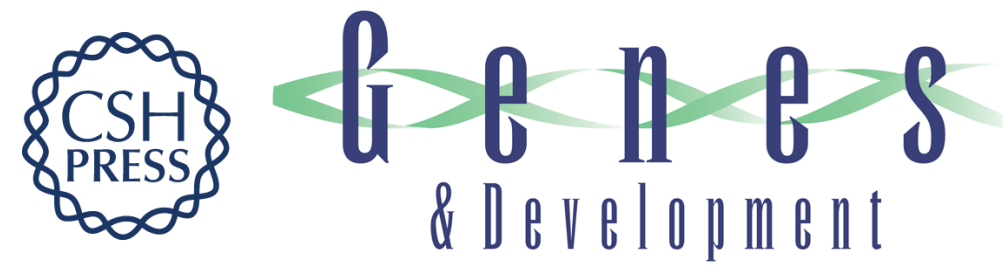

\section{An Eph receptor sperm-sensing control mechanism for oocyte meiotic maturation in Caenorhabditis elegans}

Michael A. Miller, Paul J. Ruest, Mary Kosinski, et al.

Genes Dev. 2003, 17:

Access the most recent version at doi:10.1101/gad.1028303

\section{Related Content A Multifaceted Meiotic Response to MSP}

Sci. STKE January , 2003 2003: tw39-TW39

References

This article cites 63 articles, 23 of which can be accessed free at: http://genesdev.cshlp.org/content/17/2/187.full.html\#ref-list-1

Articles cited in:

http://genesdev.cshlp.org/content/17/2/187.full.html\#related-urls

\section{License}

Email Alerting

Receive free email alerts when new articles cite this article - sign up in the box at the top Service right corner of the article or click here.

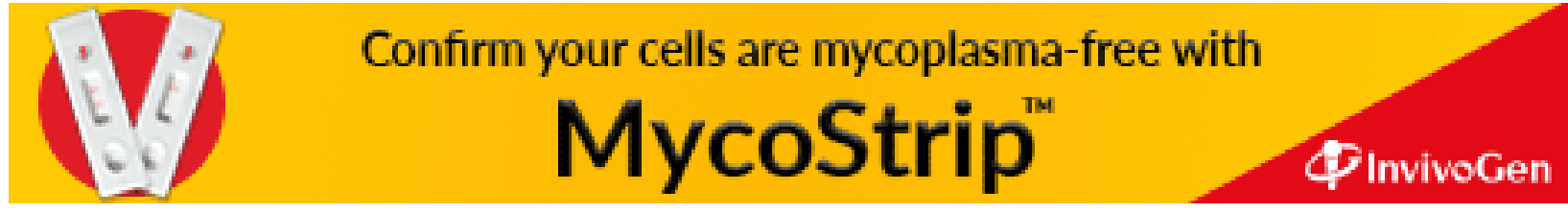

